depend on the activity of the stoker. In a practical art it is necessary to provide such margin of safety as is possible. I am, Sirs, yours faithfully,

London, Oct. 11th, 1905. WOLF DEFRIES.

\section{BREAKING UP THE STREETS.}

\section{To the Editors of THE LANCET.}

SIRs,-My attention has been called to the remarks in your issue of Oct. 7th in which you condemn the London Hydraulic Power Company in very strong terms for its action in breaking up the recently laid paving in Regentstreet.

The company was not to blame. The premises to which you refer have been supplied with power, since they were built, from a main in the back street through a private yard this yard is now being built over and it was only after the new paving work on the east side of Regent-street had been completed that the company received notice that the service pipe would have to be removed. It thus became necessary to supply the premises from Regent-street by laying a new service main from the west side.

This case illustrates the impossibility of providing against the breaking up of new pavings, even with the best intentions and desire on the part of the companies or undertakers to consult the convenience of the public and to carry out the wishes of the local authority. Except to a limited extent the works required cannot be ascertained beforehand. With our streets constructed as they usually are, without subways, inconvenience is inevitable and even where subways exist they are frequently not in the right place or are of unsuitable construction. Therefore, all that can be done is to lessen the inconvenience as much as possible. The whole expense of street openings and making good is paid by the company and it is therefore to its interest to do any necessary work in advance of repaving so as to lessen the cost. The company is always ready to comply with any reasonable direction of the local authorities in the execution of such works.

\section{I am, Sirs, yours faithfully,}

F. M. BENDALL

Secretary, London Hydraulic Power Company.

Palace-Chambers, Bridge-street, S.W., Oct. 13th, 1905.

\section{DRUNKENNESS AND ALCOHOLISM.}

\section{To the Editors of THE LANCET.}

SIRS,--Your annotation under this heading in THE LANCET of Oct. 14th is, I think, very important both from the pathological and social standpoint. Drunkenness, so far as my experience and observation show, is a common failing amongst a mining population, but the diseases usually associated with chronic alcoholism, such as brain, liver diseases, and peripheral neuritis, are unexpectedly and peculiarly infrequent. I therefore conclude that drunkenness and chronic alcoholism are not sequential. I attribute this largely, if not entirely, to the fact that in the mining district with which I am most familiar beer is the staple drink and so long as a man sticks to his beer chronic alcoholism does not follow. I am not now discussing the question whether beer whets the appetite for more potent drinks. Beer is consumed in enormous quantities, especially at the weels's end in this part of the country, but it rarely, if ever, leads to chronic alcoholism unless alcohol in a more potent form is also imbibed. The occasional drunkard appears to suffer little, except some temporary functional derangement, and I believe many every week-end drunkards make excellent workmen and seem not much the worse for it physically if they are fairly abstemious, work during the week, and start with a fair constitution. With the chronic soaker, especially of strong spirituous liquor, the results are entirely different and most disastrous. It is such persons who exhibit the pathological features of the chronic alcoholic and the law as presently carried out does not influence them ; moreover, that tendency just now shown to do away with the house where beer only is consumed is harmful. Perhaps some of your contributors can give the relative amount of inefficiency and disease caused by beer or spirits, or can give comparative information bearing upon this point from the countries where one or other is the staple article of consumption.-I am, Sirs, yours faithfully,

$$
\text { R. Prosser WHite, }
$$

Oct. 18th, 1905 Infirmary, Wigan.

\section{SANATORIUMS AND THE ERADICATION} OF CONSUMPTION.

To the Editors of $\mathrm{THE}$ LANCET.

SiRs, - The letter from Dr. W. B. H. Wood in THE LANCET of Oct. 14th, p. 1137, is of value in its emphatic recommendation that medical practitioners should distinguish phthisis in its earliest stages and advise cases to be placed promptly under sanatorium treatment-the best treatment at present known. Now, nothing would operate more certainly and promptly towards encouraging early diagnosis and the ensuing best advice being given than compulsory notification of the disease throughout the kingdom, carrying with it the usual penalties for failing. Cases could then be recommended for removal to an institution for special treatment. I would suggest that early diagnosis be founded upon the finding of tubercle bacilli in the sputum and special facilities should be given by local public bodies for promptly subjecting sputum to microscopical examination, the work being done for any medical practitioner applying either free or for a nominal fee. Nothing would prevent patients from being properly treated in suitable institutions should their medical advisers consider phthisis to be imminent while no bacilli were yet present. The stimulus towards early diagnosis which notification would bring would also have the effect of further advice being given as to what steps should be taken in order to prevent other cases of the disease from developing by the practitioner or medical officer of health investigating on the spot the probable cause of any case notified. Thus unhealthy dwellings, employments, and any other conditions might be indicated. Under notification and a more rigorous public health discipline we should soon bring down the death-rate from consumption-and even other diseases as well-for where consumption is there also must be favourable surroundings for other diseases.

I am, Sirs, yours faithfully

Porchester-place, W., Oct. 16th, 1905. HAYDN BROWN.

\section{MEDICINE AND RELIGION.}

To the Editors of THE LANCET.

SIRS, - It is not necessary to dilate on the extent and character of the evils for which the craze of Christian Science has been responsible. We all have known or read of valuable lives sacrificed which might have been saved or prolonged by skilled attention; of trivial ailments growing through neglect to causes of persistent and painful disablement; and-perhaps most tragic of all-of children allowed to linger in suffering as vicarious victims of the blind fanaticism of their parents, and dying without even the solace that delusion may bring to the incorrigible dupe. Surely this revival of the patria potestas is a strange anomaly in a society where justice puts the duty of defending the children of the poor so high, even above its function of punishing the wrongdoer, in the case of the inscription over our newest temple of Themis.

These mischievous results of Christian Science in cases of physical disease were evidently present to the minds of the speakers at the Church Congress, though their utterances on the subject might well have been more robust. But they appear to have been much less conscious of other effects which are perhaps graver, and which by their character should have special claim on the attention of divines. I refer to the influence that this creed exercises on the mental and moral health of its votaries. One would have expected, for instance, that men of experience in human nature would have been more keenly alive to the danger of a state of mental exaltation "impervious to all representations of reason and common sense," and that they would have recognised that such a condition engendered by delusion was not likely to make for sanity or for rational religion. And one would have thought, further, that the natural antipathy which the healthy mind must experience for this morbid temper would be increased by the knowledge that such notions. lent themselves to easy exploitation at the hands of knaves and hypocrites. The demoralising influence that is thereby exercised, not merely on the emotional dupes who are the victims of this quackery but on the whole community who are treated to the spectacle of successful and unrebuked humbug, ought surely to be a matter of grave concern to those who have so large and responsible a part in the moulding of public opinion. 